\title{
The Mechanism of Physical Activity-induced Amelioration of Parkinson's Disease: A Narrative Review
}

\author{
Piotr Gronek $^{1}$, Aline Nogueira Haas ${ }^{2}$, Wojciech Czarny ${ }^{3}$, Robert Podstawski ${ }^{4}$, Marcela do Santos \\ Delabary $^{2}$, Cain CT Clark ${ }^{5}$, Michał Boraczyński ${ }^{6 *}$, Maria Tarnas ${ }^{1}$, Paulina Wycichowska ${ }^{1}$, \\ Mariola Pawlaczyk ${ }^{7}$, Joanna Gronek ${ }^{1}$
}

${ }^{1}$ Laboratory of Genetics, Department of Health Sciences, Poznań University of Physical Education, Poznań, Poland. ${ }^{2}$ School of Physical Education, Physiotherapy and Dance, Federal University of Rio Grande do Sul, Porto Alegre, Brazil. ${ }^{3}$ Department of Human Sciences, University of Rzeszów, Poland. ${ }^{4}$ Department of Tourism, Recreation and Ecology, University of Warmia and Mazury in Olsztyn, Olsztyn, Poland. ${ }^{5}$ Faculty of Health and Life Sciences, Coventry University, Coventry, United Kingdom. ${ }^{6}$ Public Health, University of Warmia and Mazury Olsztyn, Poland. ${ }^{7}$ Department of Geriatric Medicine and Gerontology, Poznań University of Medical Sciences, Poznań, Poland.

[Received February 20, 2020; Revised April 3, 2020; Accepted April 7, 2020]

\begin{abstract}
Physical activity, together with its ameliorative effects on Parkinson's disease (PD) symptoms, remains a relatively unappreciated factor which may be beneficial for the treatment outcome. Contemporary evidence supports the positive effects of non-pharmacological approaches to PD symptom management, in particular the effects of the exercise on both, motor and non-motor symptoms. The aim of the study was to review the mechanisms of exercise-induced amelioration of PD symptoms. Methods: Electronic databases (PubMed, Web of Science and Google Scholar) were searched using the following key words: "Parkinson and physical activity" OR "Parkinson disease and exercise" OR "Parkinson disease and lifestyle factors" $O R$ "Parkinson disease and longevity". A total of 97 studies which investigated PD genetics and various forms of exercise and their etiologic impact on PD were reviewed. The studies were subdivided into four topic groups: 1) genetics of PD, 2) exercise and the brain, 3) physical activity and PD, 4) mind-body interventions, and discussed accordingly. Adequate levels of physical activity are associated with higher quality of life in PD patients. Physical activity may have protective and stimulatory effects for better functional efficiency in higher-level cognitive networks. It can also improve balance and motor functions by improving muscle strength. Given the etiologic evidence of the beneficial effects of physical activity on PD, albeit tentative, a concerted effort to elucidate the processes and outcomes of physical activity on ameliorating symptoms of PD must be undertaken.
\end{abstract}

Key words: Parkinson disease, physical activity, motor symptoms, cognitive networks, mind-body interventions

The year 2017 marked the 200-year anniversary of the initial diagnosis of Parkinson's Disease (PD) described by James Parkinson [1]. However, despite remarkable progress in our understanding of PD etiology and pathogenesis [2], certain key questions remain unresolved. PD is also known as older person's disease, although a growing percentage of patients have been diagnosed with early-onset parkinsonism subdivided into cases with onset before age 21 years (juvenile parkinsonism) and those with onset at or above age 21 years (young onset Parkinson disease [YOPD]) [3]. PD is the second most common age-related neurological

*Correspondence should be addressed to: Dr. Michał Boraczyński, Chair of Public Health, University of Warmia and Mazury, 14C Żołnierska St., PL-10719 Olsztyn, Poland. E-mail: michal.boraczynski@gmail.com.

Copyright: () 2020 Gronek P et al. This is an open-access article distributed under the terms of the Creative Commons Attribution License, which permits unrestricted use, distribution, and reproduction in any medium, provided the original author and source are credited. 
disorder, marked by degeneration and the loss of predominantly dopaminergic neurons in the substantia nigra [4], associated with intracellular, insoluble $\alpha$ synuclein $(\alpha-$ Syn) aggregates, localized to Lewy bodies and within neuronal processes, termed Lewy neurites. PD involves both, motor and non-motor symptoms (NMS), affecting 7-10 million people around the world [5]. It is estimated that 2,802 per 100,000 persons in North America, Europe and Australia are affected by PD [6], with the main symptoms manifesting as bradykinesia (slow movement), tremor, rigidity (increased muscle tone), postural instability, altered gait pattern, freezing of gait and motor coordination deficits $[7,8]$ and shortened stride length [9].

The visible symptoms are connected with motor control and mobility in general, however most patients are also affected by NMS, including bladder dysfunction [10], pain [11], insomnia [12], cognitive impairment and dementia [13], depression and anxiety [14], osteoporosis [15], constipation [16], apathy [17], and general fatigue [18], with the general effect of fatigue on human performance in older adults remaining the topic of debate [19].

Contemporary evidence supports the positive effects of non-pharmacological approaches to PD symptom management, in particular, the effect of the exercise on both, motor and non-motor symptoms [20]. Exercise is speculated to be underutilized due to various reasons, chief among them limited knowledge on its therapeutic potential [21]. Unfortunately, many patients with Parkinson's disease lead a sedentary lifestyle due to their combined physical limitations and mental changes [22]. Therefore, in 2010 a multifaceted and individually tailored training programme to improve PA in sedentary patients with PD was developed (ParkFit) [23]. The implementation of this programme led to greater participation in specific elements of physical activity (PA) and showed an improved physical fitness among ParkFit patients. While pharmacotherapy is essential in PD therapy, the combination of medication and PA may constitute a conceivable way to minimize various disease-induced limitations [24, 25].

A number of questions concerning PA and its ameliorative effects on PD symptoms (such as volume, intensity, type of PA, including the optimal intensity and volume per week, the timing of the exercise intervention relative to disease onset, and likewise type of exercise necessary for maximal neuroprotection and neurorestoration) have not yet been precisely defined and researchers lack consensus on the matter [26].

Given the potential for PA to alleviate symptoms of $\mathrm{PD}$, and in the absence of the consensus, the aim of the study was to review the mechanisms of exercise-induced amelioration of PD symptoms.

\section{MATERIALS AND METHODS}

\section{Search strategy}

The search focused on PD in relation to PA. Electronic databases (PubMed, Web of Science and Google Scholar) were searched using the following keywords: "Parkinson and physical activity" OR "Parkinson disease and exercise" OR "Parkinson disease and lifestyle factors" OR "Parkinson disease and longevity".

\section{Study Characteristics}

Multiple searches in each of the selected databases and additional searches for relevant references and citations were conducted. The eligibility criteria in the selection process were used to identify experimental or observational studies on PD in relation to PA or exercise at any age. Only articles written in English between January 2000 and August 2017 were considered. Two of the authors assessed all titles and abstracts and all full-text articles. The decision to accept or reject a paper was made by the first and the second author. A third, independent reviewer helped achieve a consensus, if needed.

\section{RESULTS AND DISCUSSION}

Out of the 2410 articles identified in the databases, 1876 studies remained after removal of the duplicates. After reading the titles and abstracts, 421 articles were excluded for not having PD patients as participants. The 1455 studies selected for phase 1 were fully read, and 1358 studies failed to meet the eligibility criteria and were excluded. Overall, 97 studies, compliant with the eligibility criteria of this research, were included. Figure 1 shows the flowchart of the studies included in this review (Fig. 1).

Following screening and detailed assessment, the included studies were subdivided into four topics: 1) genetics of PD, 2) exercise and the brain, 3) PA and PD, 4) mind-body interventions, and discussed accordingly.

\section{Genetics of PD}

Although the environmental factors play an essential role in the development of PD [27,28], recent studies have suggested that a number of genes influence susceptibility to this neurodegenerative disorder, including the $\alpha$-Syn gene $[29,30]$, autosomal recessive juvenile parkinsonism (AR-JP) [31], PTEN-induced putative kinase 1 (PINK1) [32], DJ-1 gene [33], and neuronal P-type ATPase gene [34].

In a large genome-wide association study (GWAS) of PD, with over 3.400 cases and 29.000 controls (the largest 
single PD GWAS cohort to date), and after controlling for age, sex, genotyping platform, and five principal components, Do et al., identified two novel regionsSCARB2 and SREBF1/RAI1-and replicated six previously reported regions-LRRK2, SNCA, GBA, MAPT, MCCC1/LAMP3, GAK and replicated a total of

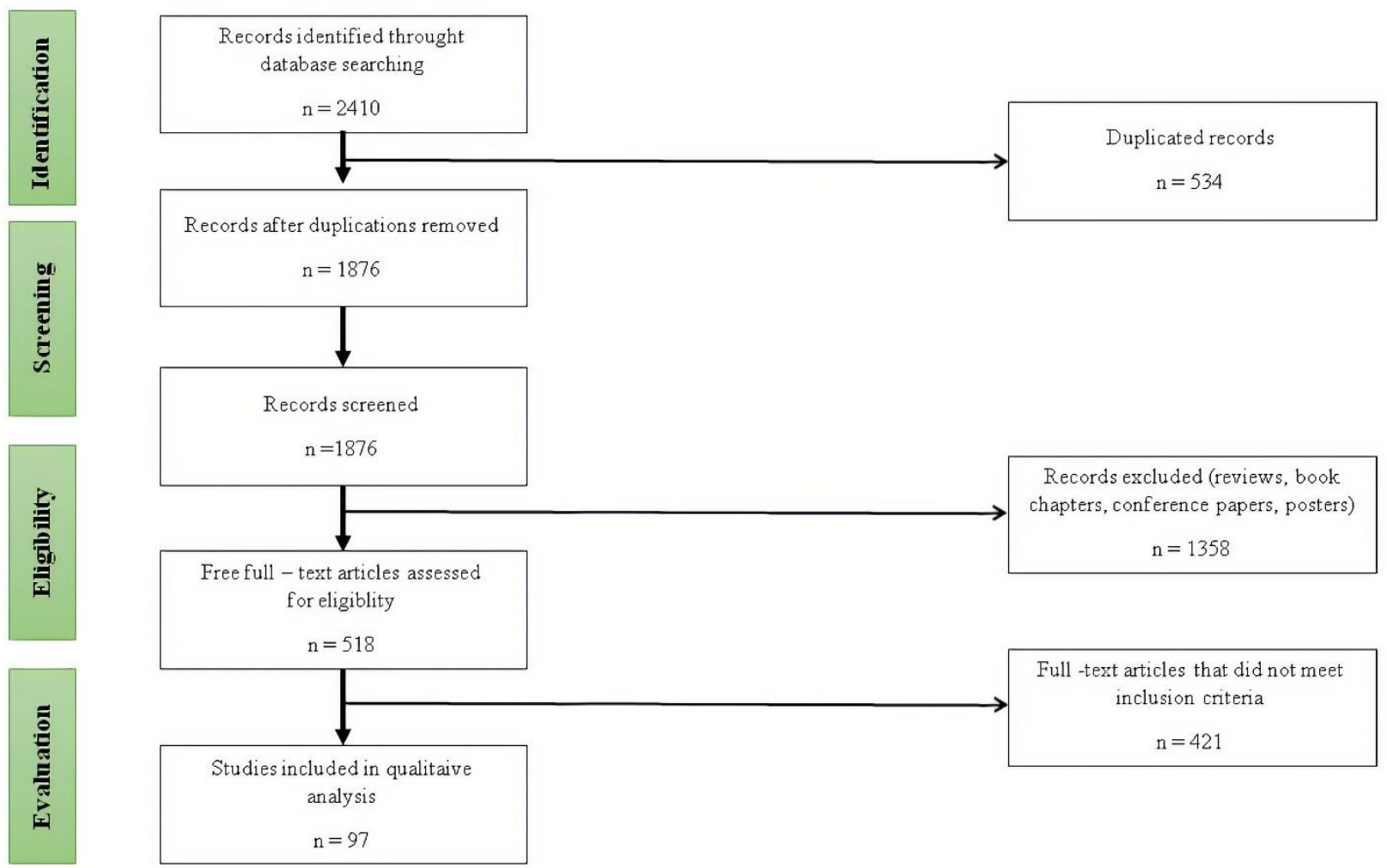

twenty previously described associations of genetic factors with PD [35].

Summarizing, it is estimated that genetic factors may contribute to at least $25 \%$ of the total variation in susceptibility of the variation to PD liability, of which currently discovered factors only explain $6 \%-7 \%$ [35], so the remaining $93 \%$ are still ambiguous.

Figure 1. Flow chart of the study selection procedures.

\section{Exercise and brain}

Certain regions of the brain routinely increase their activity while performing attention-demanding cognitive tasks, whereas others habitually decrease their activity [36]. The frontoparietal (FP) network, Default Mode Network (DMN) and the fronto-executive network (FE) act on the basis of the efficient communication between the frontal cortex and the rest of the brain. Aging negatively affects these networks and, as a consequence, specific dysfunctions of the brain networks appear [37]. Daydreaming, mind-wandering, thinking, planning for the future and autobiographical memory intensively activate the DMN $[38,39]$. This network has been relatively welldescribed, and it is known to include brain structures such as parahippocampal and hippocampal, posterior cingulate, ventral and superior frontal medial cortices, and bilateral lateral occipital, middle frontal, and middle temporal cortices [36,38]. Decreased DMN activity is associated with deteriorating working memory [40] and performance of executive function tasks in older adults $[41,42]$. The important question remains whether exercise can ameliorate the dysfunction of the aging brain. Voss et al., [37] used functional magnetic resonance imaging (fMRI) to examine low-frequency $(0.008<f<0.08 \mathrm{~Hz})$ coherence of cognitively relevant and sensory brain networks in older adults (1-year intervention trial, walking), and compared the effects of nonaerobic and aerobic fitness training on brain function and cognition. The authors highlighted that aerobic training improved the aging brain's resting functional efficiency in higherlevel cognitive networks. Attributed to PA, functional connectivity within the DMN and the Frontal Executive Network significantly increased, ameliorating, in particular brain dysfunction in the aging subjects. 
Exercise is an essential impulse for various cells (e.g. myocytes) to upregulate the expression of insulin-like growth factor type 1 (IGF-1) $[43,44]$, brain neurons to increase production of neurotrophic factors such as brainderived neurotrophic factor (BDNF) $[45,46]$ and limiting for neuroinflammation [47,48]. Moreover, exercise regulates plasticity in the hippocampus and the cortex [49], CA1 and entorhinal cortex [50,51], and increases fine discrimination [52]. The effect of PA, especially on the nervous system, results in increased molecular adaptations in neuronal function [53]. However, many of the mechanisms by which exercise exerts its effects in the brain remain largely unknown.

Figure 2 shows the summary of the main pathways effect of aerobic exercise on the nervous system (Fig. 2).

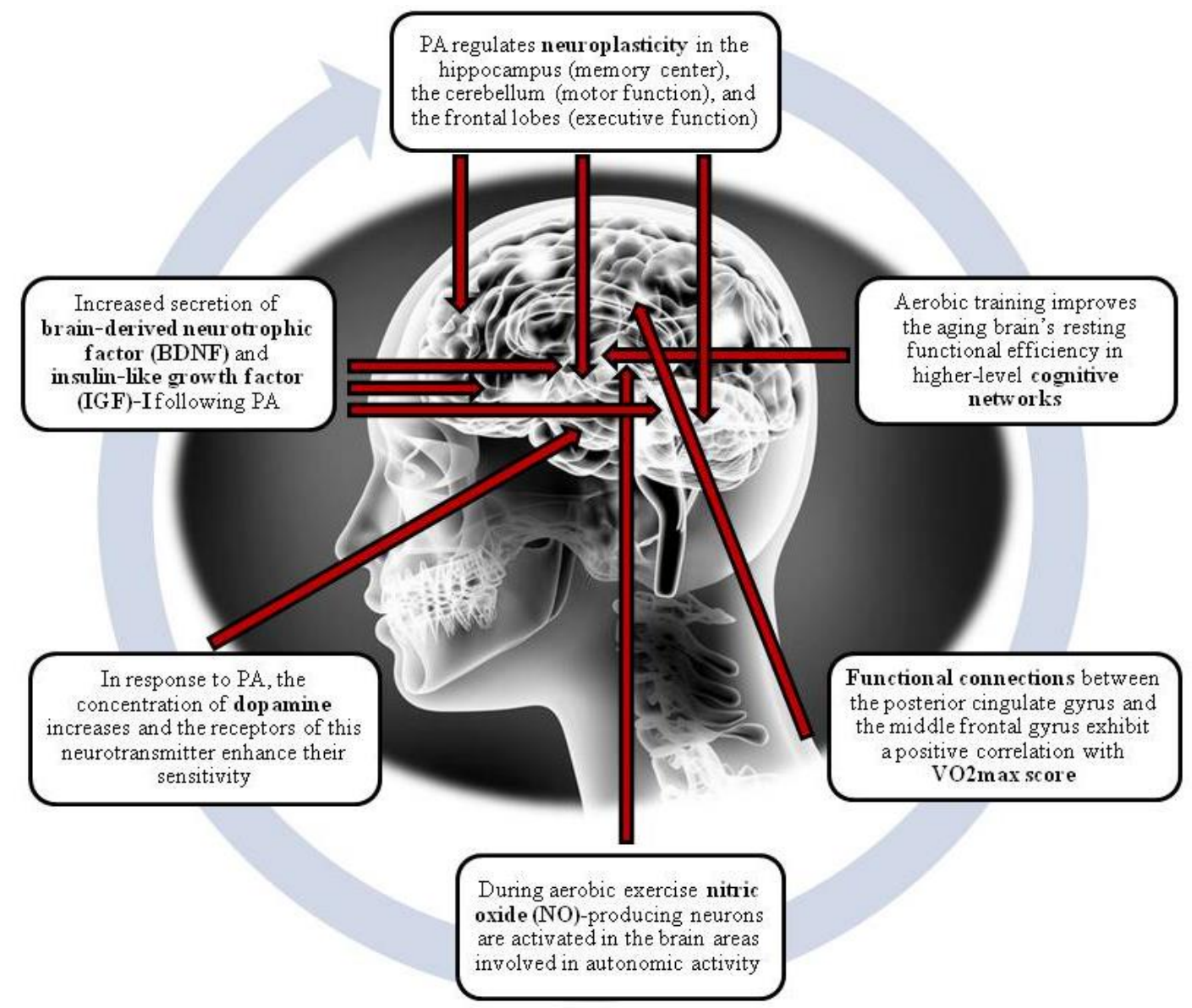

Figure 2. Summary of the main pathways effect of aerobic exercise on the nervous system.

Exercise - Human movements and physical activities involving large muscle groups, rather than highly specific, relatively non-taxing movements of small muscle groups. Exercise includes dance, callisthenics, games, and more formal activities such as jogging, swimming, and running [54]

Physical activity - Any form of body movement that has a significant metabolic demand. Thus, physical activities include training for and participation in athletic competitions, the performance of strenuous occupations, doing household chores, and non-sporting leisure activities that involve physical effort [54].
Studies on animal models have shown that aerobic exercise can, putatively, reverse the decline in neurogenesis and memory function [55,56,57], exert positive influence on cognition (especially hippocampussupported learning and memory) [58], and increase the volume of grey matter in the region of the right EC. Moreover, Duchesne et al., [59] suggested that aerobic exercise training can reduce the symptoms in the early stages of PD, not only eliciting improved physical fitness, but also motor learning capacity, which is useful in habitual activities through increased plasticity in motorrelated structures [59]. The effects of physical activity, 
both endurance and weight training, on brain function have been discussed in detail in a review paper by $\mathrm{Di}$ Liergo et al. [60].

\section{Physical activity in Parkinson's Disease}

During the analyzed period, 2410 articles on the health benefits of physical activity in PD were published, including 379 Randomized Clinical Trials (RCTs). Besides pharmacotherapy, a number of complementary approaches have become available; a) aerobic and anaerobic exercise, b) complementary and alternative medicine (CAM), with mind-body medicine being the most commonly used form in the USA [61], and c) dance, as the transitive approach including both, PA and some CAM elements. Sufficient exercise improves aerobic and anaerobic fitness, indirectly eliciting general health benefits, and improves motor habitual behaviors, especially in PD patients. Whilst aerobic training is generally operationalized in a standardized manner, anaerobic exercise (i.e. 10 -m maximal walking speed tests or peak power for leg press) is often used interchangeably with resistance training or with strength training, and therefore warrants careful interpretation. Resistance training is generally concerned with lower loads and more repetitions than the general strength training, which is usually a combination of the two types of hypertrophy: i.e. myofibrillar hypertrophy (increased myofibril size), where contractions against $80 \%$ to $90 \%$ of the maximal voluntary contraction (MVC) occur and sarcoplasmic hypertrophy (increased in myocytes glycogen storage). In summary, strength exercise, powerstrength exercise, strength-endurance exercise are numerous terminologies associated with training activity, and each must be carefully interpreted and operationalized cautiously, per individual capability.

\section{Aerobic exercise}

Concurrent motor impairment in PD $[62,63,64,65]$ and ways of eliciting improvement in habitual activities, motor performance, ambulation and the overall functional independence [66], remain the challenge of the contemporary physical therapy modalities. Continuous exercise training for 12 weeks in mouse model of Parkinson's disease (MPD) showed that, in spite of the drastic loss of dopaminergic neurons and depletion of dopamine in the severe chronic MPD, endurance exercise training effectively reverses the Parkinson's like behavioral deficits related to regular movement, balance and gait performance. Unfortunately, long-term exercise training did not reverse the habitual learning deficit in chronic MPD [67]. Given the potential of the aerobic exercise to elicit such positive adaptations, its use should be advocated. Notwithstanding, more randomized controlled trials in humans are required to obtain any consensus.

\section{Muscle strength}

Analysis of the studies which investigated muscle strength is more complicated than studying aerobic training (mostly walking, cycling) since a plethora of different modalities and terminologies are available, including the maximal voluntary contraction and the rate of force development [68], peak muscle power [69], onehand grip, and pinch strength [70], muscle isometric contraction $[26,69,70,71,72,73]$, and other physical tests and no instrumental evaluation [26]. A systematic review of the effectiveness of strength training, performed against a different resistance from body weight, in improving motor and non-motor symptoms in patients with PD recently concluded that strength training appears to be a suitable PA to improve a number of physical parameters, especially maximal voluntary contraction, the rate of force development, balance, reaction time, gait speed and many others. Moreover, quality of life parameters assessed by different questionnaires: UPDRSII, Parkinson's Disease Questionnaire, Parkinson's Disease Quality of Life Scale, and Beck Depression Inventory were also improved in PD subjects [74,75].

Investigating the effects of physiotherapy with concurrent strength training (ST) and aerobic training (AT) on motor symptoms, functional capacity, and electroencephalographic (EEG) activity in PD patients, Carvalho et al., [26] observed that aerobic and strength training, controlled by parameters of intensity, duration, and frequency, showed a greater improvement than conventional physical therapy as far as symptoms and cortical activity of PD patients were concerned: strength training - improvement by $27.5 \%$ (effect size $[\mathrm{ES}]=1.25$, confidence interval $[\mathrm{CI}]=-0.11,2.25)$, aerobic training by $35 \%(\mathrm{ES}=1.34, \mathrm{CI}=-0.16,2.58)$, physiotherapy group - by $2.9 \%(\mathrm{ES}=0.07, \mathrm{CI}=-0.85,0.99)[26]$.

\section{Mind-body interventions}

Mind-body therapies which can be applied in PD patients include systems associated with kinesthesia, such as Yoga [76], Tai-chi [77], or Qigong (part of the Tai-chi system) [78]. In this area, dance has emerged as an important tool in the complementary to pharmacotherapy treatment of PD patients.

Other possibilities include systems which are not associated with movement, such as mindfulness-based cognitive therapy (MBCT) [79], meditation [80], breathing techniques [81], hypnosis [82,83] and biofeedback [84]. 
Yoga

During the analyzed period, 32 articles were published, including 3 RCTs and 29 systematic reviews on the health benefits of Yoga in PD. Recently, Yoga practice has increasingly been used for enhancing well-being, stress reduction, and improving coping with chronic diseases of aging, and various neurodegenerative disorders such as PD [85,86,87]. In Poland $80 \%$ of all Yoga practitioners are female and $12.5 \%$ have Ph.D. or higher education, thus it could be stated that this kind of PA is popular among well-educated women [88].

Analyzing the use of Yoga only in the context of PD, a number of benefits come to mind. Firstly, the use of inexpensive interventions which combine movement, chanting, with breath practices and meditation, can help achieve some therapeutic goals via non-pharmacological stress reduction, brain enhancement exercise, lifestyle changes [80], and appears to improve mood, coping with chronic stress, and provides relief of chronic pain [89].

Secondly, Yoga exercises are less strenuous as compared to many others so they can be used in older adults with physical limitations and many of the practices may be adapted to a sitting or horizontal position. Finally, Yogic activity, including meditation, is a safe, nonpharmacologic approach, thus reducing polypharmacy. PD progression is the consequence of the loss of predominantly dopaminergic neurons in the substantia nigra, and the concentration of dopamine decrease [4], Kjaer et al., [90], using 11C-raclopride PET, in vivo, demonstrated a $65 \%$ increase in endogenous dopamine release in the ventral striatum and conscious experience during Yoga Nidra meditation, suggesting that while meditating, a suppression of cortico-striatal glutamatergic transmission occurs [90].

\section{Tai-chi and Qigong}

The reviewing process identified 63 articles, including 10 RCTs and 53 systematic reviews on the health benefits of Tai-chi and Qigong in PD. Tai-chi, also known as T'ai chi ch'uan or Taiijiquan, is a meditative martial art which can be considered as a mind-body exercise [91]. Since Qigong is a part of the Tai-chi system, these techniques may be analyzed together.

Tai-chi consists of a series of dance-like movements flowing smoothly from one position to another, emphasizing weight transfer during kinesthesia of the body. All transitions are integrated with breathing and finally linked in a continuous sequence [92]. All movements are characterized by a low-impact and simple flow, which is the fundamental reason for their acceptance by the older people.
Parallel to motor function deterioration, which is typical for PD, falling, which is the result of muscles weakness, balance problems and freezes, is one of the most common problems in Parkinson's patients [93, 94]. Following Qigong scheduled exercises, 5 times per week for $60 \mathrm{~min}$. each time (10 $\mathrm{min}$. for warm-up, $40 \mathrm{~min}$. for the exercise, and $10 \mathrm{~min}$. for cooldown), showed significant improvement in muscle hardness, timed "up and go", balance, and hand-eye coordination (the turnover-jars test) [78]. Moreover, Tai-chi has been shown to significantly improve balance [95], strength of the lower limbs [96], and flexibility [97].

In summary, Tai-chi and Qigong might be considered complementary to medications. The combined approach could achieve superior results; however, it should be emphasized that their role is not to cure but help maintain as much normal function as possible in the affected individuals.

\section{Dance in $P D$}

There is strong evidence to suggest that exercise programs for patients with PD can improve mobility [98], balance [99], strength [100], and consequently, quality of life [101].

In the last 10 years, several studies have sought to investigate the effects of dance on people with Parkinson's. As part of the review process, 19 RCTs on the health benefits of dance in PD were identified. The RCTs generally focused on coordination, balance, functional mobility, spatial cognition in PD. In addition to mind-body medical approaches to exercise such as Yoga, Tai Chi, dance has also been studied as an appropriate and useful intervention [102].

Dance is often associated with ballroom dancing, often out of reach for the ordinary, physically non-active person, however there are numerous types and styles of dances which are studied in the context of older adults, including ballroom [103, 104], various types of Latin $[105,106]$ traditional $[107,108,109]$, and contemporary dance $[110,111]$.

Music and body movement are the common features of all styles and types of dance. Dance may be a relevant form of physical activity, especially in PD and older adults, due to the fact that the range of intensity, and flexibility may be adapted to individuals. Dancing may be a popular mode of leisure time for older people. However, it is still alarming that physical activity of $60 \%$ Americans over the age of 65 is much lower than recommended [112]. Additionally, it has been shown that dancing is associated with improvement in mobility [103], balance [113] and quality of life [109].

Gait difficulties observed in PD patients concern forward walking, but also backward walking, such as 
stepping back from a curb as a swiftly moving bus passes, as well as in older people, whose walking is characterized by lesser cadence, increased double support time, and shorter stride length and swing phase [114]. Also, Hackney and Earhart [115, 116] observed that during backward walking, gait speed and stride length in those individuals are reduced as compared to healthy controls.

Most of the RCTs in the area of dance for Parkinson's propose tango as an intervention. Tango is defined by many short steps, alternately smooth and sharp, and for this reason it could be an interesting and promising therapy for improving gait, balance, and mobility, while also reducing disease severity in PD $[113,116]$.

\section{Clinical significance and implications}

Recent RCTs have highlighted a possible association between PA or exercise and PD therapy. Exercise training, in early-stage PD, can also promote better motor learning capacity through increased plasticity in motorrelated structures [59]. Carvalho et al., [26] found that combining classical physiotherapy with concurrent strength exercise and aerobic exercise - controlled by parameters of intensity, duration, and frequency, on motor symptoms, functional capacity, and EEG activity in PD patients the aerobic and strength training - resulted in greater improvement than conventional physical therapy as far as symptoms and cortical activity of PD patients were concerned [26].

The crucial accidence concerned falling, which is a common problem in PD, with significant risk of body injury. Resistance exercise, Tai chi, Yoga, and dance can improve mobility, balance, and strength, especially of the lower limbs, and by strengthening the muscles and improving balance, decrease falls and, as a consequence, improve quality of life among PD patients [101].

Yoga, being less strenuous as compared to many other exercises, can be used by older adults with physical limitations and may be adapted to a sitting or horizontal position.

\section{Conclusions}

It is safe to conclude that the presented studies provide compelling evidence that regular exercise could improve muscle strength, balance and motor functions in PD patients. Further research is necessary to determine whether physical activity may have protective and stimulatory effects for better functional efficiency in higher-level cognitive networks.

\section{References}

[1] Parkinson J (2002). An essay on the shaking palsy. 1817. J Neuropsychiatry Clin Neurosci, 14(2): 223-36; discussion 222.

[2] Jankovic J (2017). Movement disorders in 2016: progress in Parkinson disease and other movement disorders. Nat Rev Neurol, 13(2):76-8.

[3] Alves G, Forsaa EB, Pedersen KF, Gjerstad MD, Larsen JP (2008). Epidemiology of Parkinson's disease. J Neurol, 255(5):18-32.

[4] Rachakonda V, Pan TH, Le WD (2004). Biomarkers of neurodegenerative disorders: how good are they? Cell Res, 14(5):347-58.

[5] Parkinson's Disease Foundation, http://www.pdf.org/, Accessed 2 May 2016.

[6] Pringsheim T, Jette N, Frolkis A, Steeves TD (2014). The prevalence of Parkinson's disease: A systematic review and meta-analysis. Mov Disord, 29:1583-1590.

[7] Bartels AL, Leenders KL (2009). Parkinson's disease: The syndrome, the pathogenesis and pathophysiology. Cortex, 45:915-921.

[8] Postuma RB, Berg D, Stern M, Poewe W, Olanow CW, Oertel W, et al. (2015). MDS clinical diagnostic criteria for Parkinson's disease. Mov Disord, 30(12):1591-601.

[9] Picelli A, Camin M, Tinazzi M, Vangelista A, Cosentino A, Fiaschi A, et al. (2010). Threedimensional motion analysis of the effects of auditory cueing on gait pattern in patients with Parkinson's disease: a preliminary investigation. Neurol Sci, 31:423-430.

[10] Sakakibara R, Uchiyama T, Yamanishi T, Shirai K, Hattori T (2008). Bladder and bowel dysfunction in Parkinson's disease. J Neural Transm, 115:443-460.

[11] Ford B. (2010). Pain in Parkinson's disease. Mov Disord, 25:98-103.

[12] Gjerstad MD, Wentzel-Larsen T, Aarsland D, Larsen JP (2007). Insomnia in Parkinson's disease: Frequency and progression over time. J Neurol Neurosurg Psychiatry, 78:476-479.

[13] Bosboom JLW, Stoffers D, Wolters EC (2004). Cognitive dysfunction and dementia in Parkinson's disease. J Neural Transm, 111:1303-1315.

[14] Walsh K, Bennett G (2001). Parkinson's disease and anxiety. Postgrad Med J, 77:89-93.

[15] Invernizzi M, Carda S, Viscontini GS, Cisari C (2009). Osteoporosis in Parkinson's disease. Parkinsonism Relat Disord, 15(5):339-346.

[16] Adams-Carr KL, Bestwick JP, Shribman S, Lees A, Schrag A, Noyce AJ (2016). Constipation preceding Parkinson's disease: a systematic review and metaanalysis. J Neurol Neurosurg Psychiatry, 87(7):710716.

[17] Pluck GC, Brown RG (2002). Apathy in Parkinson's disease. J Neurol Neurosurg Psychiatry, 73:636-642.

[18] Friedman JH, Brown RG, Comella C, Garber CE, Krupp LB, Lou J-S, et al. (2007). Fatigue in Parkinson's disease: A review. Mov Disord, 22:297-308. 
[19] Enoka RM, Duchateau J (2016). Translating Fatigue to Human Performance. Med Sci Sports Exerc, 48(11):2228-2238.

[20] Olanow CW, Watts RL, Koller WC (2001). An algorithm (decision tree) for the management of Parkinson's disease: treatment guidelines. Neurology, 56 (11 Suppl 5):S1-88.

[21] Cusso ME, Donald KJ, Khoo TK (2016). The Impact of Physical Activity on Non-Motor Symptoms in Parkinson's Disease: A Systematic Review. Front. Med, 3:35.

[22] Van Nimwegen M, Speelman AD, Hofman-van Rossum EJ, Overeem S, Deeg DJ, Borm GF, et al. (2011). Physical inactivity in Parkinson's disease. J Neurol, 258:2214-21.

[23] Van Nimwegen $M$, Speelman AD, Smulders K, Overeem S, Borm GF, Backx FJ, et al. (2010). Design and baseline characteristics of the ParkFit study, a randomized controlled trial evaluating the effectiveness of a multifaceted behavioral program to increase physical activity in Parkinson patients. BMC Neurol, 10:70.

[24] Doshay LJ (1962). Method and value of exercise in Parkinson's disease. N Engl J Med, 267:297-299.

[25] Von Werssowetz OF (1964). Parkinsonism. Thomas, Springfield, IL.

[26] Carvalho A, Barbirato D, Araujo N, Martins JV, Cavalcanti JLS, Santos TM, et al. (2015). Comparison of strength training, aerobic training, and additional physical therapy as supplementary treatments for Parkinson's disease: pilot study. Clin Interv Aging, 10:183-191.

[27] Searles Nielsen S, Gallagher LG, Lundin JI, Longstreth Jr, WT, Smith-Weller T, Franklin GM, et al. (2012). Environmental tobacco smoke and Parkinson's disease. Mov Disord, 27:293-6.

[28] O'Reilly ÉJ, Chen H, Gardener H, Gao X, Schwarzschild MA, Ascherio A (2009). Smoking and Parkinson's disease: using parental smoking as a proxy to explore causality. Am J Epidemiol, 169:678-82

[29] Polymeropoulos MH, Lavedan C, Leroy E, Ide SE, Dehejia A, Dutra A, et al. (1997). Mutation in the alphasynuclein gene identified in families with Parkinson's disease. Science, 276:2045-2047.

[30] Singleton AB, Farrer M, Johnson J, Singleton A, Hague S, Kachergus J, et al. (2003). Alpha-Synuclein locus triplication causes Parkinson's disease. Science, 302:841.

[31] Kitada T, Asakawa S, Hattori N, Matsumine H, Yamamura Y, Minoshima S, et al. (1998). Mutations in the parkin gene cause autosomal recessive juvenile parkinsonism. Nature, 392:605-608.

[32] Valente EM, Abou-Sleiman PM, Caputo V, Muqit MM, Harvey K, Gispert S, et al. (2004). Hereditary earlyonset Parkinson's disease caused by mutations in PINK1. Science, 304:1158-1160.

[33] Bonifati V, Rizzu P, van Baren MJ, Schaap O, Breedveld GJ, Krieger E, et al. (2003). Mutations in the DJ-1 gene associated with autosomal recessive earlyonset parkinsonism. Science, 299:256-259.
[34] Ramirez A, Heimbach A, Gründemann J, Stiller B, Hampshire D, Cid LP, et al. (2006). Hereditary parkinsonism with dementia is caused by mutations in ATP13A2, encoding a lysosomal type 5 P-type ATPase. Nat Genet, 38(10):1184-1191.

[35] Do CB, Tung JY, Dorfman E, Kiefer AK, Drabant EM, Francke U, et al. (2011). Web-based genomewide association study identifies two novel loci and a substantial genetic component for parkinson's disease. PLoS Genetics, 7(6): Article ID e1002141.

[36] Fox MD, Snyder AZ; Vincent JL, Corbetta M, Van Essen DC, Raichle ME (2005). The human brain is intrinsically organized into dynamic, anticorrelated functional networks. Proceedings of the National Academy of Sciences of the United States of America, 102(27):9673-678.

[37] Voss MW, Prakash RS, Erickson KI, Basak C, Chaddock L, Kim JS, et al. (2010). Plasticity of brain networks in a randomized intervention trial of exercise training in older adults. Front Ag Neurosci, 2:32.

[38] Buckner RL, Andrews-Hanna JR, Schacter DL (2008). The brain's default network: anatomy, function, and relevance to disease. Ann NY Acad Sci, 1124:1-38.

[39] Schilbach L, Eickhoff SB, Rotarska-Jagiela A, Fink GR, Vogeley K (2008). Minds at rest? Social cognition as the default mode of cognizing and its putative relationship to the "default system" of the brain. Conscious Cogn, 17:457-467.

[40] Hampson M, Driesen NR, Skudlarski P, Gore JC, Constable RT (2006). Brain connectivity related to working memory performance. J Neurosci, 26:1333813343 .

[41] Andrews-Hanna JR, Snyder AZ, Vincent JL, Lustig C, Head D, Raichle ME, et al. (2007). Disruption of largescale brain systems in advanced aging. Neuron, 56:924935.

[42] Damoiseaux JS, Beckmann CF, Arigita EJS, Barkhof F, Scheltens P, Stam CJ, et al. (2008). Reduced restingstate brain activity in the "default network" in normal aging. Cereb Cortex, 18:1856-1864.

[43] Cotman CW, Berchtold NC, Christie LA (2007). Exercise builds brain health: key roles of growth factor cascades and inflammation. Trends Neurosci, 30(9):464-72.

[44] Vivar C, Potter MC, van Praag H (2013). All about running: synaptic plasticity, growth factors and adult hippocampal neurogenesis. Curr Top Behav Neurosci, 15:189-210.

[45] Cotman C, Berchtold N (2002). Exercise: a behavioral intervention to enhance brain health and plasticity. Trends Neurosci, 25(6):295-301.

[46] Sleiman SF, Chao MV (2015). Downstream consequences of exercise through the action of BDNF. Brain Plasticity, 143-8.

[47] Kohman RA, Kohman RA, Bhattacharya TK, Wojcik E, Rhodes JS. (2013). Exercise reduces activation of microglia isolated from hippocampus and brain of aged mice. J Neuroinflammation, 10(1):114.

[48] Barrientos RM, Frank MG, Crysdale NY, Chapman TR, Ahrendsen JT, Day HE, et al. (2011). Little 
exercise, big effects: reversing aging and infection induced memory deficits, and underlying processes. $\mathbf{J}$ Neurosci, 31(32):11578-86.

[49] Pereira AC, Huddleston DE, Brickman AM, Sosunov AA, Hen R, McKhann GM, et al. (2007). An in vivo correlate of exercise-induced neurogenesis in the adult dentate gyrus. Proc Natl Acad Sci USA, 104:5638-43.

[50] Stranahan AM, Khalil D, Gould E (2007). Running induces widespread structural alterations in the hippocampus and entorhinal cortex. Hippocampus, 17:1017-22.

[51] Siette J, Westbrook RF, Cotman C, Sidhu K, Zhu W, Sachdev P, et al. (2013). Age-specific effects of voluntary exercise on memory and the older brain. Biol Psychiatry, 73:435-42.

[52] Creer DJ, Romberg C, Saksida LM, van Praag H, Bussey TJ (2010). Running enhances spatial pattern separation in mice. Proc Natl Acad Sci USA, 107:236772.

[53] Morgan JA, Corrigan F, Bernhard TB. (2015). Effects of physical exercise on central nervous system functions: a review of brain region specific adaptations. J Mol Psychiatry, 3:3.

[54] Kent M. (2007). Oxford dictionary of sports science and medicine. J Sport Sci Med, 6.

[55] van Praag H (2008). Neurogenesis and exercise: past and future directions. Neuromolecular Med, 10(2):12840.

[56] Marlatt MW, Lucassen PJ, van Praag H (2010). Comparison of neurogenic effects of fluoxetine, duloxetine and running in mice. Brain Res, 1341:93-9.

[57] Opendak M, Gould E (2015). Adult neurogenesis: a substrate for experience dependent change. Trends Cogn Sci, 19:151-61.

[58] Whiteman AS, Young DE, Budson AE, Stern CE, Schon K (2016). Entorhinal volume, aerobic fitness, and recognition memory in healthy young adults: A voxel-based morphometry study. NeuroImage, 126:229-238

[59] Duchesne C, Gheysen F, Bore A, Albouy G, Nadeau A, Robillard ME, et al. (2016). Influence of aerobic exercise training on the neural correlates of motor learning in Parkinson's disease individuals. NeuroImage: Clinical, 12:559-569.

[60] Di Liegro CM, Schiera G, Proia P, Di Liegro I. (2019). Physical Activity and Brain Health. Genes, 10:720.

[61] Barnes PM, Powell-Griner E, McFann K, Nahin RL (2004). Complementary and alternative medicine use among adults: United States, 2002. Adv Data, 343:1-19.

[62] Ceravolo MG, Paoloni L, Provinciali L (2001). Rehabilitation of parkinsonian patients. Funct Neurol, 16:157-162.

[63] Picelli A, Melotti C, Origano F, Waldner A, Fiaschi A, Santilli V, et al. (2013). Robot-assisted gait training in patients with Parkinson's disease. Neurodegener Dis Manag, 3:321-330.

[64] Tomlinson CL, Patel S, Meek C, Herd CP, Clarke CE, Stowe R, et al. (2013). Physiotherapy versus placebo or no intervention in Parkinson's disease. Cochrane Database Syst Rev, 9:CD002817.
[65] Ferrazzoli D, Ortelli P, Cucca A, Bakdounes L, Canesi M, Volpe, D. (2020). Motor-cognitive approach and aerobic training: a synergism for rehabilitative intervention in Parkinson's disease. Neurodegener Dis Manag, 10(1), 41-55.

[66] Lau YS, Patki G, Das-Panja K, Le WD, Ahmad SO (2011). Neuroprotective effects and mechanisms of exercise in a chronic mouse model of Parkinson's disease with moderate neurodegeneration. Eur $\mathbf{J}$ Neurosci, 33:1264-1274.

[67] Pothakos K, Kurz MJ, Lau YS (2009). Restorative effect of endurance exercise on behavioral deficits in the chronic mouse model of Parkinson's disease with severe neurodegeneration. BMC Neurosci, 10(1):6.

[68] Schlenstedt C, Paschen S, Kruse A, Raethjen J, Weisser B, Deuschl G (2015). Resistance versus balance training to improve postural control in Parkinson's disease: a randomized rater blinded controlled study. PLoS One, 10(10):e0140584

[69] Paul SS, Canning CG, Song J, Fung VS, Sherrington C (2014). Leg muscle power is enhanced by training in people with Parkinson's disease: a randomized controlled trial. Clin Rehabil, 28(3):275-288.

[70] Mateos-Toset S, Cabrera-Martos I, Torres-Sánchez I, Ortiz-Rubio A, González-Jiménez E, Valenza MC (2016). Effects of a single hand-exercise session on manual dexterity and strength in persons with Parkinson disease: a randomized controlled trial. PMR, 8(2):115-122.

[71] Combs SA, Diehl MD, Chrzastowski C, Didrick N, McCoin B, Mox N, et al. (2013). Community-based group exercise for persons with Parkinson disease: a randomized controlled trial. NeuroRehabilitation, 32(1):117-124

[72] Corcos DM, Robichaud JA, David FJ, Leurgans SE, Vaillancourt DE, Poon C, et al. (2013). A two-year randomized controlled trial of progressive resistance exercise for Parkinson's disease. Mov Disord, 28(9):1230-1240.

[73] Dibble LE, Foreman KB, Addison O, Marcus RL, LaStayo PC (2015). Exercise and medication effects on persons with Parkinson disease across the domains of disability: a randomized clinical trial. J Neurol Phys Ther, 39(2):85-92.

[74] Ramazzina I, Bernazzoli B, Costantino C (2017). Systematic review on strength training in Parkinson's disease: an unsolved question. Clin Interv Aging, 12:619-628.

[75] Tidman M, Skotzke E (2020). Effects of a communitybased exercise program on mobility, balance, cognition, sleep, activities of daily living, and quality of life in PD: a pilot study. Neurodegener Dis Manag, 10:27-39.

[76] Colgrove YS, Sharma N, Kluding P, Potter D, Imming K, VandeHoef J, et al. (2012). Effect of Yoga on Motor Function in People with Parkinson's Disease: A Randomized Controlled Pilot Study. J Yoga Phys Ther, 2:112.

[77] Huston P, McFarlane B (2016). Health benefits of tai chi What is the evidence? Can Fam Physician, 62:88190 . 
[78] Liu XL, Chen S, Wang Y (2016). Effects of health qigong exercises on relieving symptoms of Parkinson's disease. Evid Based Complement Alternat Med, 2016.

[79] Fitzpatrick L, Simpson J, Smith A (2010). A qualitative analysis of mindfulness-based cognitive therapy (MBCT) in Parkinson's disease. Psychol Psychother, 83(2):179-192.

[80] Acevedo BP, Pospos S, Lavretsky H (2016). The Neural Mechanisms of Meditative Practices: Novel Approaches for Healthy Aging. Curr Behav Neurosci Rep, 3(4):328-339.

[81] Bidikar MP, Jagtap GJ, Chakor RT (2014). Influence of Deep Breathing on Heart Rate Variability in Parkinson's Disease: Co-relation with Severity of Disease and Non-Motor Symptom Scale Score. J Clin Diagn Res, 8(7):BC01-3.

[82] Stambaugh EE (1977). Hypnotic treatment of depression in the Parkinsonian patient: a case study. Am J Clin Hypn, 19(3):185-6.

[83] Elkins G, Sliwinski J, Bowers J, Encarnacion E (2013). Feasibility of clinical hypnosis for the treatment of Parkinson's disease: a case study. Int J Clin Exp Hypn, 61(2):172-182.

[84] Harrington W, Greenberg A, King E, McNames J, Holmstrom L, Horak FB, et al. (2016). Alleviating Freezing of Gait using phase-dependent tactile biofeedback. Conf Proc IEEE Eng Med Biol Soc, 5841-5844.

[85] Jain FA, Nazarian N, Lavretsky H (2014). Feasibility of central meditation and imagery therapy for dementia caregivers. Int J Geriatr Psychiatry, 29(8):870-6.

[86] Siddarth D, Siddarth P, Lavretsky H (2014). An observational study of the health benefits of yoga or tai chi compared with aerobic exercise in communitydwelling middle-aged and older adults. Am J Geriatr Psychiatry, 22(3):272-3.

[87] Black DS, Cole SW, Irwin MR, Breen E, Cyr NMS, Nazarian N. et al. (2013). Yogic meditation reverses $\mathrm{NF}-\kappa \mathrm{B}$ and IRF-related transcriptome dynamics in leukocytes of family dementia caregivers in a randomized controlled trial. Psychoneuroendocrinology, 38(3):348-55.

[88] Social Diagnosis 2015. Social Diagnosis 2000-2013. Objective and Subjective Quality of Life in Poland.

[89] Field T (2011). Yoga clinical research review. Complement Ther Clin Pract, 17(1):1-8.

[90] Kjaer TW, Bertelsen C, Piccini P, Brooks D, Alving J, Lou HC (2002). Increased dopamine tone during meditation-induced change of consciousness. Brain Res Cogn Brain Res, 13(2):255-9.

[91] Wayne PM, Gagnon MM, Macklin EA, Travison TG, Manor B, Lachman M, et al. (2017). The Mind Body-Wellness in Supportive Housing (Mi-WiSH) study: Design and rationale of a cluster randomized controlled trial of Tai Chi in senior housing. Contemp Clin Trials, 60:96-104.

[92] Wang C, Bannuru R, Ramel J, Kupelnick B, Scott T, Schmid CH (2010). Tai Chi on psychological wellbeing: systematic review and meta-analysis. BMC Complem Altern M, 10:23.
[93] Wood BH, Bilclough JA, Bowron A, Walker RW (2002). Incidence and prediction of falls in Parkinson's disease: a prospective multidisciplinary study. J Neurol Neurosurgery Psychiatry, 72(6):721-725.

[94] Boonstra TA, Van Der Kooij H, Munneke M, Bloem BR (2008). Gait disorders and balance disturbances in Parkinson's disease: clinical update and pathophysiology. Current Opinion in Neurology, 21(4):461-471.

[95] Chan WW, Bartlett DJ (2000). Effectiveness of tai chi as a therapeutic exercise in improving balance and postural control. Phys Occup Ther Geriatr, 17(3):1-22.

[96] Liu B, Liu ZH, Zhu HE, Mo JC, Cheng DH (2011). Effects of tai chi on lower limb myodynamia in the elderly people: a meta-analysis. J Tradit Chin Med, 31(2):141-6.

[97] Huang Y, Liu X (2015). Improvement of balance control ability and flexibility in the elderly tai chi chuan (TCC) practitioners: a systematic review and metaanalysis. Arch Gerontol Geriatr, 60(2):233-8.

[98] Ashburn A, Fazakarley L, Ballinger C, Pickering R, McLellan LD, Fitton C (2007). A randomized controlled trial of a home based exercise programme to reduce the risk of falling among people with Parkinson's disease. J Neurol Neurosurg Psychiatry, 78(7):678-684.

[99] Hirsch MA, Toole T, Maitland CG, Rider RA (2003). The effects of balance training and high- intensity resistance training on persons with idiopathic Parkinson's disease. Arch Phys Med Rehabil, 84(8):1109-1117.

[100] Li F, Harmer P, Fitzgerald K, Eckstrom E, Stock R, Galver J, et al. (2012). Tai chi and postural stability in patients with Parkinson's disease. N Engl J Med, 366(6):511-519.

[101] Soh SE, Morris ME, McGinley JL (2011). Determinants of health-related quality of life in Parkinson's disease: a systematic review. Parkinsonism Relat Disord, 17(1):1-9.

[102] Earhart GM, Falvo MJ (2013). Parkinson disease and exercise. Compr Physiol, 3:833-848.

[103] Borges EG, Cader SA, Vale RG, Cruz TH, Carvalho MC, Pinto FM, et al. (2012). The effect of ballroom dance on balance and functional autonomy among the isolated elderly. Arch Gerontol Geriatr, 55:492-6.

[104] Borges EGD, Vale RGD, Cader SA, Leal S, Miguel F, Pernambuco CS, et al. (2014). Postural balance and falls in elderly nursing home residents enrolled in a ballroom dancing program. Arch Gerontol Geriatr, 59:312-6.

[105] McKinley P, Jacobson A, Leroux A, Bednarczyk V, Rossignol M, Fung J (2008). Effect of a communitybased Argentine tango dance program on functional balance and confidence in older adults. J Aging Phys Act, 16:435-53.

[106] Granacher U, Muehlbauer T, Bridenbaugh SA, Wolf M, Roth R, Gschwind Y, et al. (2012). Effects of a salsa dance training on balance and strength performance in older adults. Gerontology, 58:305-12.

[107] Sofianidis G, Hatzitaki V, Douka S, Grouios G (2009). Effect of a 10-week traditional dance program on static 
and dynamic balance control in elderly adults. J Aging Phys Act, 17:167-80.

[108] Janyacharoen T, Laophosri M, Kanpittaya J, Auvichayapat P, Sawanyawisuth K (2013). Physical performance in recently aged adults after 6 weeks traditional Thai dance: a randomized controlled trial. Clin Interv Aging, 8:855-9.

[109] Eyigor S, Karapolat H, Durmaz B, Ibisoglu U, Cakir S (2009). A randomized controlled trial of Turkish folklore dance on the physical performance, balance, depression and quality of life in older women. Arch Gerontol Geriatr, 48:84-8.

[110] Coubard OA, Ferrufino L, Nonaka T, Zelada O, Bril B, Dietrich G (2014). One month of contemporary dance modulates fractal posture in aging. Front Aging Neurosci, 6:1-12.

[111] Ferrufino L, Bril B, Dietrich G, Nonaka T, Coubard OA (2011). Practice of contemporary dance promotes stochastic postural control in aging. Front Hum Neurosci, 5:169.
[112] Macera CA, Ham SA, Yore MM, Jones DA, Ainsworth BE, Kimsey CD, et al. (2001). PEER REVIEWED: Prevalence of physical activity in the United States: Behavioral Risk Factor Surveillance System, 2001. Prevent Chronic Dis, 2(2):A17.

[113] Hackney ME, Kantorovich S, Levin R, Earhart GM (2007). Effects of tango on functional mobility in Parkinson's disease: a preliminary study. J Neurol Phys Ther, 31:173-9.

[114] Laufer Y (2005). Effect of age on characteristics of forward and backward gait at preferred and accelerated walking speed. J Gerontol A Biol Sci Med Sci, 60(5):627-32.

[115] Hackney ME, Earhart GM (2010). Effects of dance on balance and gait in severe Parkinson disease: a case study. Disabil Rehabil, 32(8):679-84.

[116] Hackney ME, Earhart GM (2010). Recommendations for Implementing Tango Classes for Persons with Parkinson Disease. Am J Dance Ther, 32(1):41-52. 